\title{
Direct Torque Control Induction Motor Drive with Improved Flux Response
}

\author{
Bhoopendra Singh, ${ }^{1}$ Shailendra Jain, ${ }^{2}$ and Sanjeet Dwivedi ${ }^{3}$ \\ ${ }^{1}$ Department of Electrical Engineering, University Institute of Technology, Rajiv Gandhi Technical University, Bhopal 462033, India \\ ${ }^{2}$ Department of Electrical Engineering, Maulana Azad National Institute of Technology, Bhopal 462051, India \\ ${ }^{3}$ Power Electronics R\&D Design Center, Danfoss Power Electronics A/s Norager, 6B, 2Th, 6400 Sonderborg, Denmark
}

Correspondence should be addressed to Bhoopendra Singh, bhoopendrasingh1@gmail.com

Received 9 May 2012; Revised 25 July 2012; Accepted 27 July 2012

Academic Editor: Don Mahinda Vilathgamuwa

Copyright (C) 2012 Bhoopendra Singh et al. This is an open access article distributed under the Creative Commons Attribution License, which permits unrestricted use, distribution, and reproduction in any medium, provided the original work is properly cited.

\begin{abstract}
Accurate flux estimation and control of stator flux by the flux control loop is the determining factor in effective implementation of DTC algorithm. In this paper a comparison of voltage-model-based flux estimation techniques for flux response improvement is carried out. The effectiveness of these methods is judged on the basis of Root Mean Square Flux Error (RMSFE), Total Harmonic Distortion (THD) of stator current, and dynamic flux response. The theoretical aspects of these methods are discussed and a comparative analysis is provided with emphasis on digital signal processor (DSP) based controller implementation. The effectiveness of the proposed flux estimation algorithm is investigated through simulation and experimentally validated on a test drive.
\end{abstract}

\section{Introduction}

In a DTC induction motor drive, a decoupled control of torque and flux can be achieved by two independent control loops [1-3]. The steady state as well as the dynamic performance of the drive is closely related to the efficient implementation of these two control algorithm. There are few well-known methods to estimate these parameters. Most of them are voltage model based [3], where the flux and torques are estimated by sensing stator voltage and current. The methods based on voltage models are most preferable for sensorless drives since these methods are less sensitive to the parameter variations and does not require motor speed or rotor position signals. However, the estimation of stator voltage when the machine is operating at low speed introduces error in flux estimation which also affects the estimation of torque and speed in case of sensorless drive [4$11]$.

In a conventional DTC drive the basic-voltage-modelbased flux estimation is carried out by integrating the back emf of the machine. A pure integrator has the following limitations.
(1) Any transduction error in measured stator current due to offset introduces DC component and hence results in integrator saturation.

(2) Integration error due to incorrect initial values.

A commonly employed solution is to replace a pure integrator with a low-pass filter $[12,13]$, however it is achieved at the expense of deteriorated low-speed operation of the drive, when the operating frequency of the drive is lower than the cutoff frequency of the low-pass filter.

Flux estimation based on the current model is most suitable for low-speed operation $[14,15]$, however it is a parameter dependent method, which require rotor speed or position. Thus parameter independent operation, which makes a DTC drive more robust and reliable compared to a FOC drive, gets affected when current-model-based flux estimation is implemented.

Most of the available literature on flux estimation and its influence on the performance of an induction-motor drive is primarily focused on sensorless field-oriented controlled drives [5-11]. The available literature on DTC drives too are mainly confined to performance enhancement in terms 
of torque ripples. Since the steady state as well as dynamic performance of a DTC drive is greatly affected by the flux control loop which in turn depends upon flux estimation algorithm. In this paper a comprehensive study on voltagemodel-based flux estimation algorithm from the perspective of their impact on the flux response of the drive, in terms of flux ripples, distortion in estimated flux due to error in stator flux sector estimation, stator current harmonics, and dynamic flux response is carried out.

\section{DTC Operation}

According to the DTC principle, an independent control of torque and flux can be achieved by the application of appropriate voltage vectors in such a way that the error between the estimated torque and flux with their respective reference values remain within the limits of hysteresis comparators. The desired voltage vectors to compensate the errors are selected based on the output of the torque and flux hysteresis comparator as well as the locus of stator flux vector.

From the basic equation governing induction motor operation stator flux $\lambda_{s}$ is given by

$$
\lambda_{s}=\int\left(V_{s}-R_{s} I_{s}\right) d t
$$

Neglecting the drop in stator resistance,

$$
\Delta \lambda_{s}=\overline{V_{s}} \Delta t,
$$

where $\Delta t$ is the time interval of application of the applied voltage vector. Electromagnetic Torque in an Induction motor is given by (3)

$$
T_{e}=P \frac{L_{m}}{\sigma L_{s} L_{r}}\left|\lambda_{s}\right|\left|\lambda_{r}\right| \sin (\delta),
$$

where

$$
\sigma=1-\frac{L_{m}^{2}}{L_{s} L_{r}} .
$$

It can be concluded from (3) that an increment in torque can be achieved by increasing the angle between stator and rotor flux vector. Splitting the vector $\Delta \lambda_{s}$ into horizontal and orthogonal components it can be concluded that orthogonal component of $\Delta \lambda_{s}$ is responsible for torque control and the horizontal component controls the flux as shown in Figure 1.

\section{Voltage Model Based Flux Estimation}

3.1. Flux Estimation with Pure Integrator. The stator flux components are computed by integration of the voltages in the stationary reference frame given by (5):

$$
\lambda_{s \alpha}=\frac{1}{s}\left(E_{s \alpha}\right), \quad \lambda_{s \beta}=\frac{1}{s}\left(E_{s \beta}\right),
$$

where

$$
\begin{aligned}
& E_{s \alpha}=v_{s \alpha}-i_{s \alpha} R, \\
& E_{s \beta}=v_{s \beta}-i_{s \beta} R .
\end{aligned}
$$

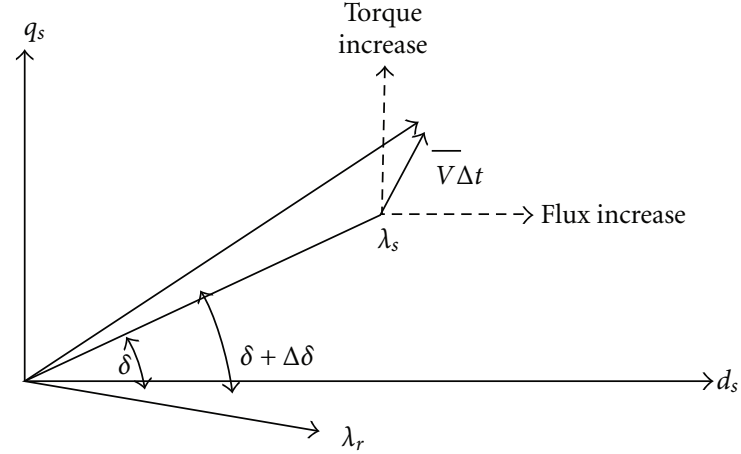

FIGURE 1: Flux and torque control by the applied voltage vector in a DTC drive.

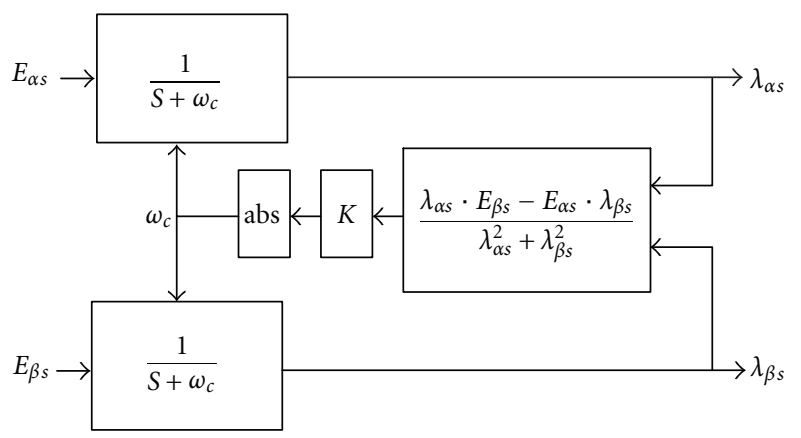

FIgure 2: Adaptive Low-pass filter.

Expressing (5) in discrete form

$$
\begin{gathered}
\lambda_{s \alpha}(k)=\Delta t_{s} \cdot E_{s \alpha}(k)+\lambda_{s \alpha}(k-1), \\
\lambda_{s \beta}(k)=\Delta t_{s} E_{s \beta}(k)+\lambda_{s \beta}(k-1),
\end{gathered}
$$

where $\lambda_{s \alpha}(k)$ and $\lambda_{s \alpha}(k-1)$ are flux linkage at the $K$ th and $(K-1)$ th sampling instant and $\Delta t_{s}$ is sampling time step.

3.2. Flux Estimation with Low-Pass Filter. A well-known solution to the dc-offset and initial value problem with a pure integrator is to replace it with a low-pass filter (LPF) with an appropriate cutoff frequency. The mathematical expression of the low-pass filter with a cutoff frequency of $\omega_{c}$ can be given as

$$
\begin{aligned}
& \lambda_{s \alpha}=\frac{1}{s+\omega_{c}}\left(E_{s \alpha}\right), \\
& \lambda_{s \beta}=\frac{1}{s+\omega_{c}}\left(E_{s \beta}\right) .
\end{aligned}
$$

Which can be expressed in discrete form as

$$
\begin{aligned}
& \lambda_{s \alpha}(k)=\frac{1}{1+\Delta t_{s} \omega_{c}}\left(\Delta t_{s} E_{s \alpha}(k)+\lambda_{s \alpha}(k-1)\right), \\
& \lambda_{s \beta}(k)=\frac{1}{1+\Delta t_{s} \omega_{c}}\left(\Delta t_{s} E_{s \beta}(k)+\lambda_{s \beta}(k-1)\right) .
\end{aligned}
$$

The value of the cutoff frequency $\omega_{c}$ has to be judicially chosen, a too low value of $\omega_{c}$ leads to a better integration 


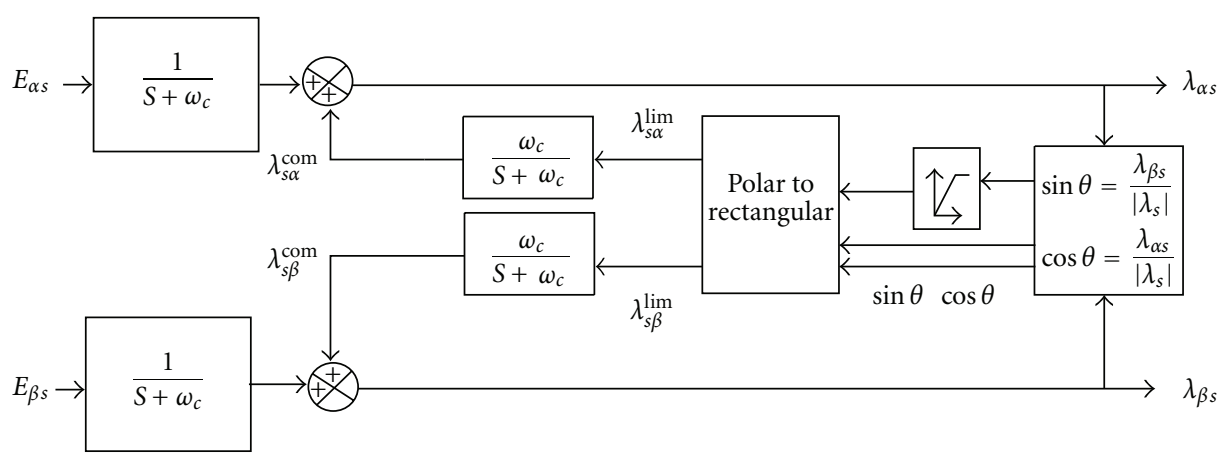

FIGURE 3: Modified low-pass filter with feedback compensation.

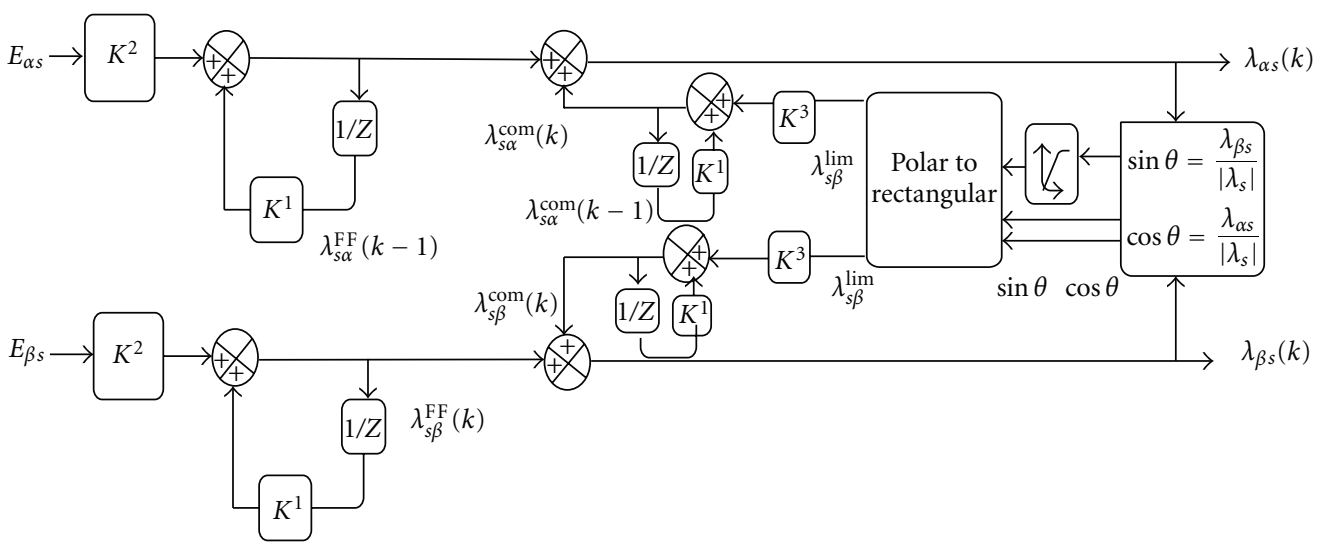

FIgURE 4: Schematic block diagram based on discrete equation.

but higher DC bias, on the contrary a cutoff frequency higher than operating frequency leads to flux distortion at low speeds. A possible solution to this problem is an adaptive LPF-based flux estimator with cutoff frequency proportional to the synchronous frequency, as shown in Figure 2. The relation between the cutoff frequency and synchronous frequency $\omega_{s}$ can be given by a simple relation $\omega_{c}=k \omega_{s}$. The typical range of $k$ lies between 0.1 and 0.5 and the synchronous frequency can be given by (12).

\subsection{Modified-Low-Pass Filter with Feedback Compensation.} The expression for the modified-low-pass filter with feedback compensation integration algorithm is given by (10). The method can be implemented as shown in Figure 3, named as Mod LPF method

$$
\lambda_{s}=E_{s} \frac{1}{s+\omega_{c}}+\lambda_{s}^{\lim } \frac{\omega_{c}}{s+\omega_{c}} .
$$

The first part of the equation represents a low-pass filter while the second part realizes a compensating feedback signal which is used to compensate the error in the output. The parameter $\lambda_{s}^{\lim }$ in the second term of new integration algorithm is the output of a saturation block, which stops the integration when the output signal exceeds the reference stator flux amplitude.
The value of $\lambda_{s}^{\lim }$ can be obtained from the sin and cosine value of the angle obtained by integrating the stator angular frequency $w_{s}$ given by (11) and (12):

$$
\theta=\int w_{s} \mathrm{~d} t
$$

where stator frequency can be given by

$$
w_{s}=\frac{E_{s \beta} \lambda_{s \alpha}-E_{s \alpha} \lambda_{s \beta}}{\left|\lambda_{s}\right|^{2}} .
$$

The accuracy of the modified flux estimation algorithm thus is strongly dependent on the value of angle $(\theta)$ which can either be obtained from the stator frequency or from the flux components $\left(\lambda_{s \alpha}, \lambda_{s \beta}\right)$. At low speeds (low frequencies), accuracy of calculation is jeopardized by the large percentage of ripple in $w_{s}$. Hence, using the ratio of sin and cosine of angle $(\theta)$ based on the estimated flux components at low speeds leads to better results than the calculation based on electrical frequency.

The final expression of the Mod LPF for implementation on a discrete controller can be developed with the help of (13)-(17)

$$
\lambda_{s}=E_{s} \frac{1}{s+\omega_{c}}+\lambda_{s} \lim \frac{\omega_{c}}{s+\omega_{c}}
$$




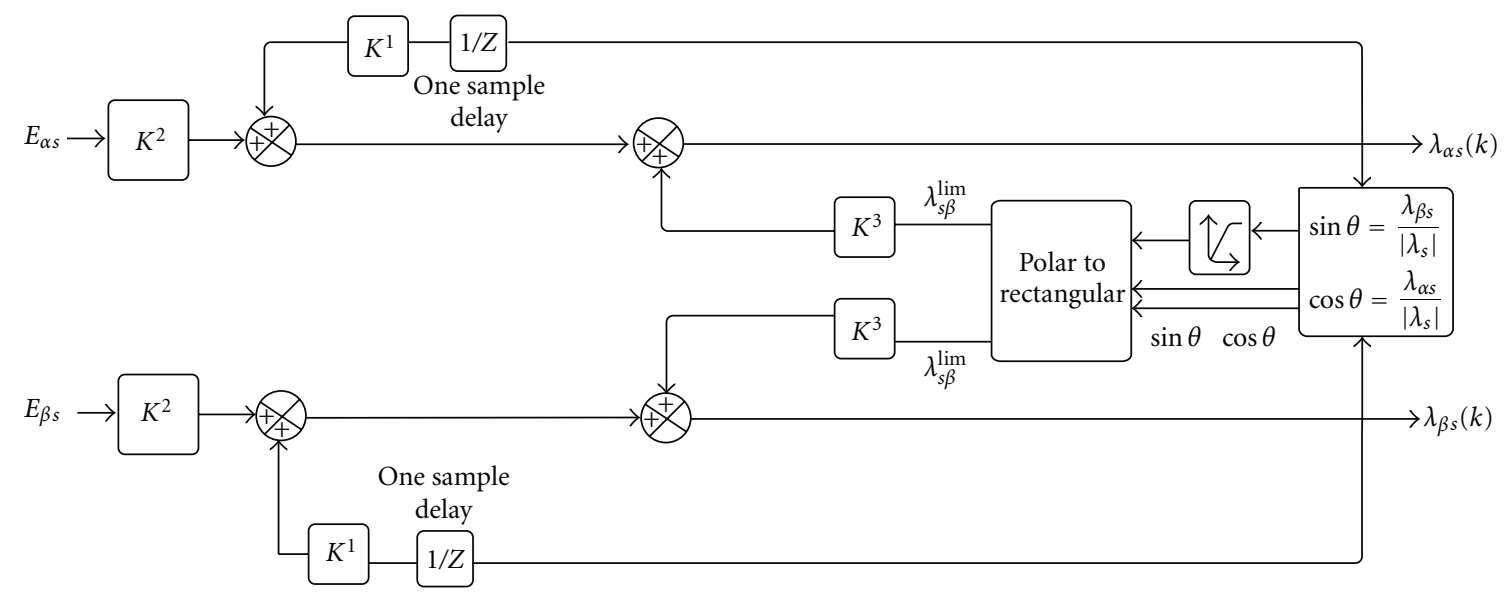

FIGURE 5: Schematic block diagram based on alternate discrete equation.

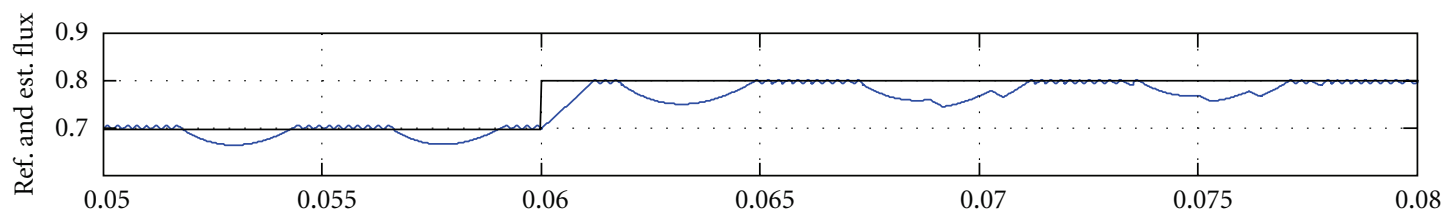

(a)

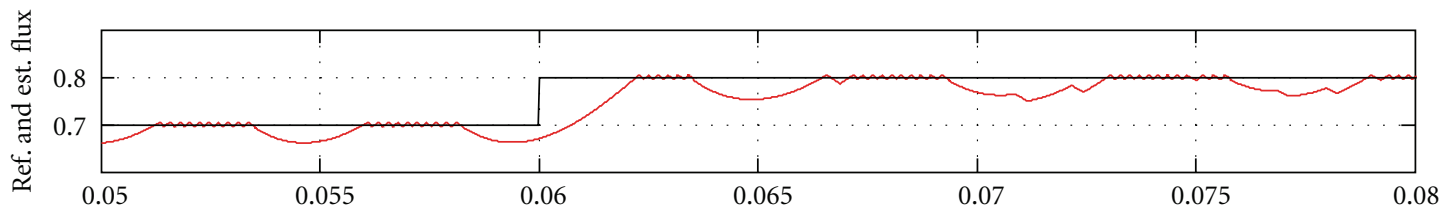

(b)

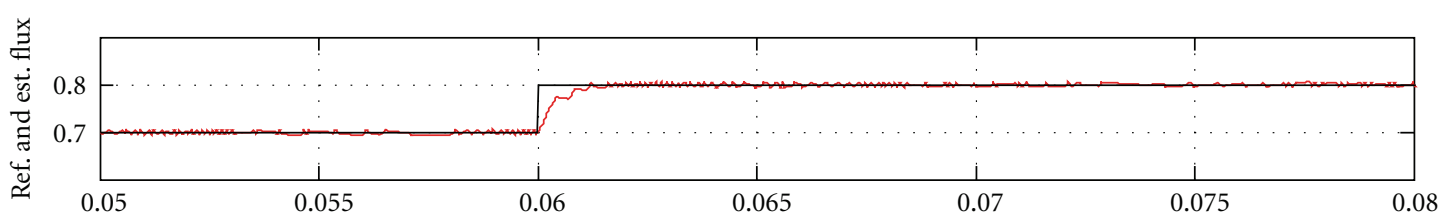

(c)

FIgURe 6: Dynamic response of estimated flux (a) pure integrator, (b) LPF and (c) Mod LPF.

$$
\lambda_{s}=\lambda_{s}^{\mathrm{FF}}+\lambda_{s}^{\mathrm{com}}
$$

where $E_{s}\left(1 /\left(s+\omega_{c}\right)\right)=\lambda_{s}{ }^{\mathrm{FF}}$ and $\lambda_{s}^{\lim }\left(\omega_{c} /\left(s+\omega_{c}\right)\right)=\lambda_{s}{ }^{\mathrm{com}}$.

The first term of equation which is feed forward component is the output of a low-pass filter, while the second term is the compensating feedback input. This can be expressed in discrete by (18):

$$
\begin{gathered}
\lambda_{s}^{\mathrm{FF}}\left(s+\omega_{c}\right)=E_{s}, \\
\lambda_{s}^{\mathrm{FF}} * s+\lambda_{s}^{\mathrm{FF}} * \omega_{c}=E_{s}, \\
\frac{\lambda_{s}^{\mathrm{FF}}(k)-\lambda_{s}^{\mathrm{FF}}(k-1)}{\Delta t_{s}}+\lambda_{s}^{\mathrm{FF}}(k) * \omega_{c}=E_{s}(k), \\
\lambda_{s}^{\mathrm{FF}}(k)=\frac{1}{1+\Delta t_{s} \omega_{c}}\left(\Delta t_{s} E_{s}(k)+\lambda_{s}^{\mathrm{FF}}(k-1)\right) .
\end{gathered}
$$

Similarly the second term can be expressed in discrete by the following equations:

$$
\begin{gathered}
\lambda_{s}{ }^{\mathrm{com}}=\lambda_{s}^{\lim \frac{\omega_{c}}{s+\omega_{c}}} \\
\lambda_{s}{ }^{\mathrm{com}}(k)=\frac{1}{1+\Delta t_{s} \omega_{c}}\left(\lambda_{s}{ }^{\mathrm{com}}(k-1)+\Delta t_{s} \omega_{c} \lambda_{s}^{\lim }(k)\right) .
\end{gathered}
$$

Let

$$
\frac{1}{1+\Delta t_{s} \omega_{c}}=K_{1}, \quad \frac{\Delta t_{s}}{1+\Delta t_{s} \omega_{c}}=K_{2}, \quad \frac{\omega_{c} \Delta t_{s}}{1+\Delta t_{s} \omega_{c}}=K_{3} .
$$

The schematic block diagram for implementation of the flux estimation algorithm on a discrete controller can be developed with the help of (18) and (20) and is shown in Figure 4. 


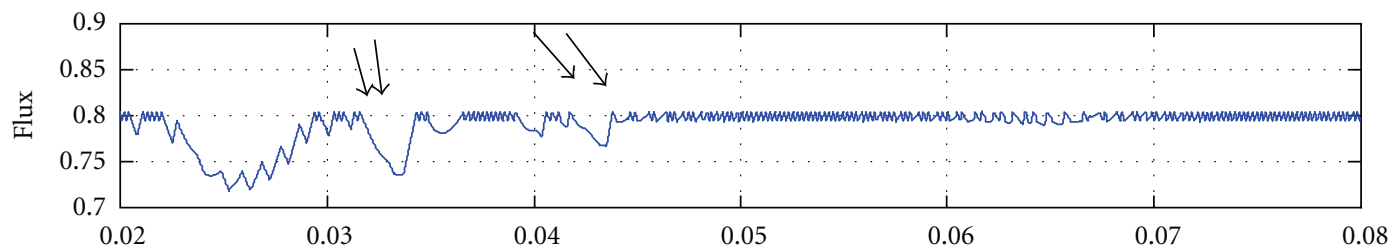

(a)

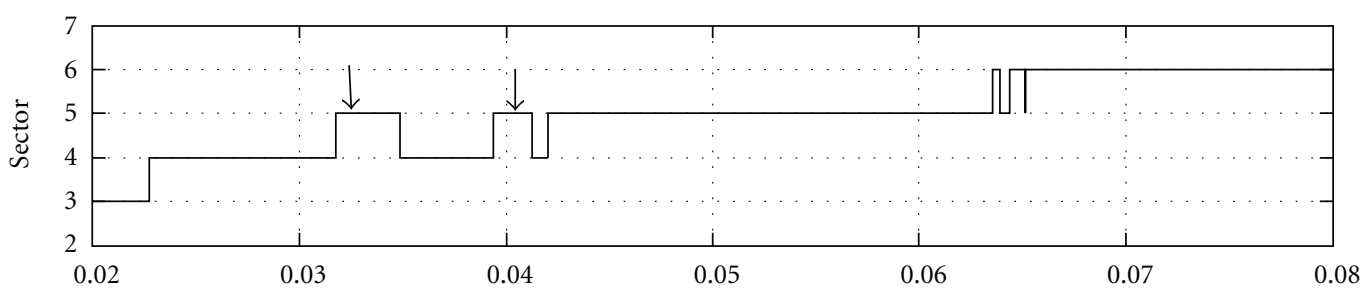

(b)

FIGURE 7: Inaccurate estimation of stator flux sector in LPF integration method and corresponding flux distortion (a) stator flux and (b) stator flux sector.

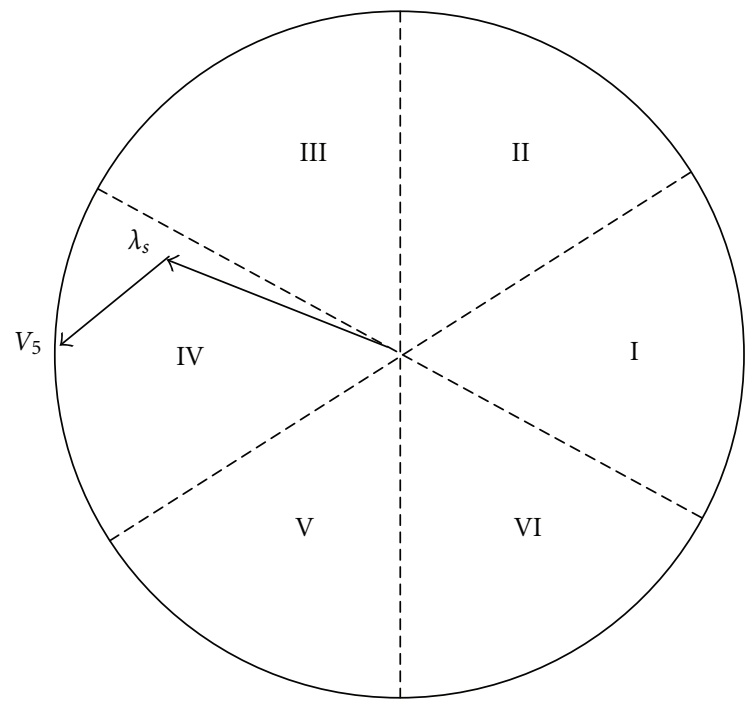

(a)

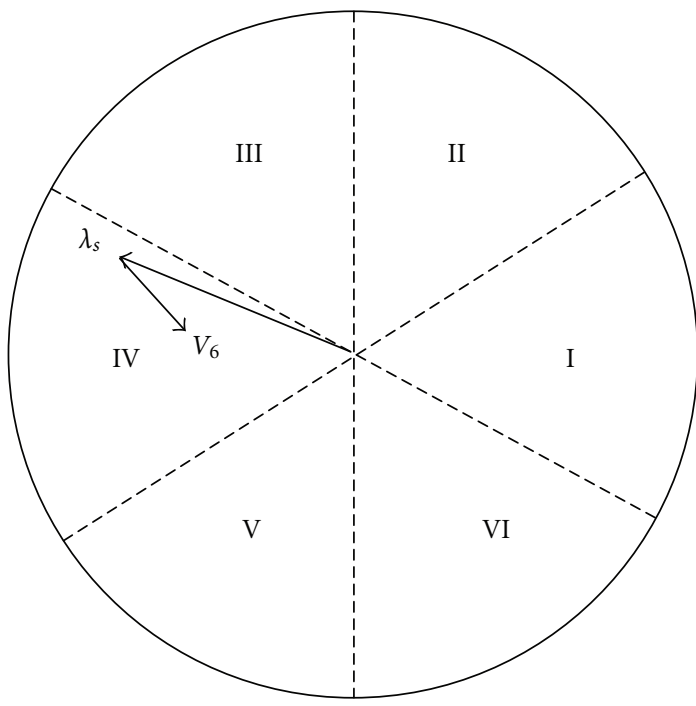

(b)

FIGURE 8: Stator flux vector in sector IV and corresponding voltage vectors for torque and flux increment. (a) Normally selected voltage vector for flux and torque increment. (b) Flux decrement by wrongly selected voltage vector due to error in sector estimation.

An alternate approach for the realization of the flux estimation algorithm given by (10) can be explained as follows.

From (10) it can be easily obtained that

$$
\begin{gathered}
\lambda_{s}\left(s+\omega_{c}\right)=E_{s}+\lambda_{s}^{\lim } * \omega_{c} \\
\frac{\lambda_{s}(k)-\lambda_{s}(k-1)}{\Delta t_{s}}+\lambda_{s}(k) * \omega_{c}=E_{s}(k)+\lambda_{s}^{\lim }(k) * \omega_{c} \\
\lambda_{s}(k)=\frac{1}{1+\Delta t_{s} \omega_{c}}\left(\Delta t_{s} E_{s}(k)\right. \\
\left.\quad+\lambda_{s}^{\lim }(k) * \omega_{c} * \Delta t_{s}+\lambda_{s}(k-1)\right)
\end{gathered}
$$

Based on (24) the schematic block diagram for implementation on a discrete controller is shown in Figure 5.

\section{Results and Discussion}

4.1. Simulation Results. A detailed comparison of the proposed flux estimation algorithm has been carried out through simulation. The simulation parameters of the test drive are given in Section 4.2. Simulations are carried to study the dynamic as well the steady state response of the estimation algorithm at $80 \%$ and $20 \%$ rated speed.

Figure 6 shows the comparison of stator flux dynamic response for a step change in reference flux $(0.7 \mathrm{wb}$ to $0.8 \mathrm{wb})$ at $500 \mathrm{rpm}$. From Figure 6 it can be clearly interpreted 


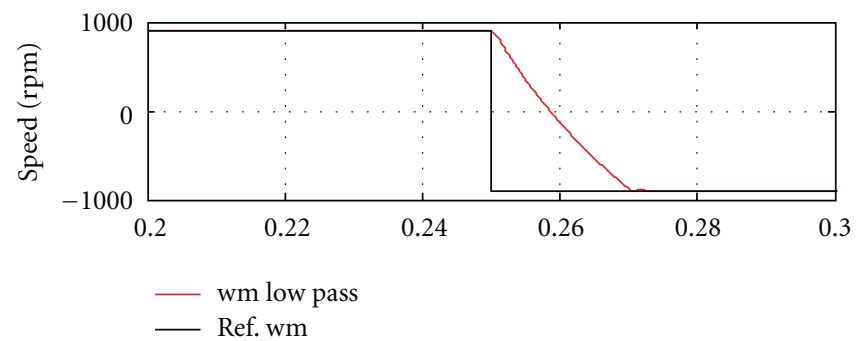

(a)

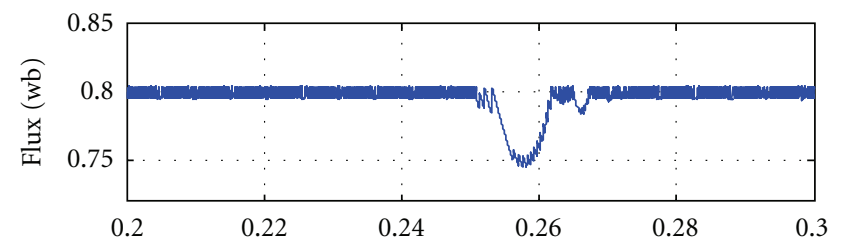

(c)

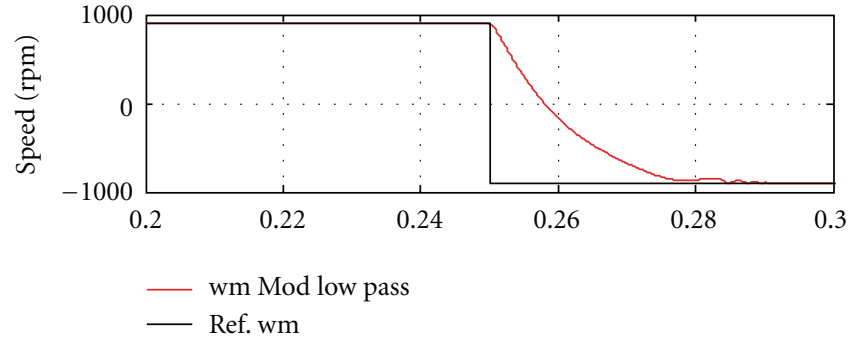

(b)

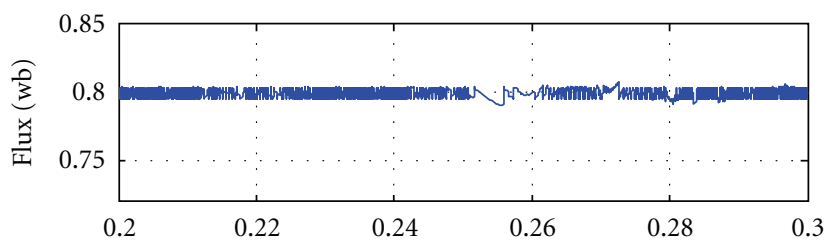

(d)

FIgURE 9: Flux response for speed reversal dynamics (a) speed in rpm (low pass), (b) Mod low pass speed, (c) flux response (low pass), and (d) flux response (Mod Low pass).

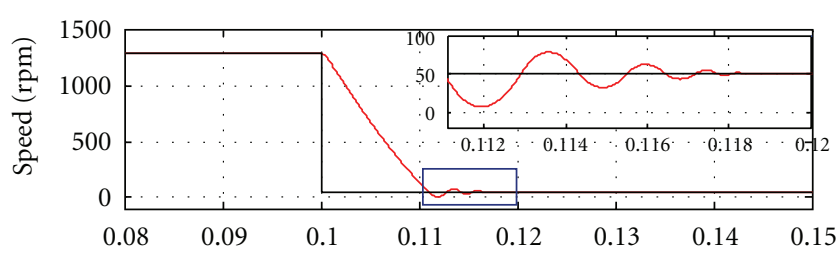

(a)

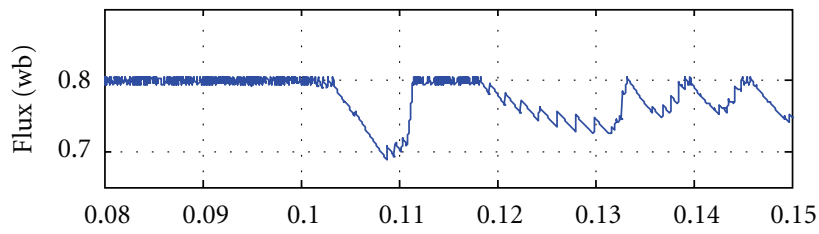

(c)

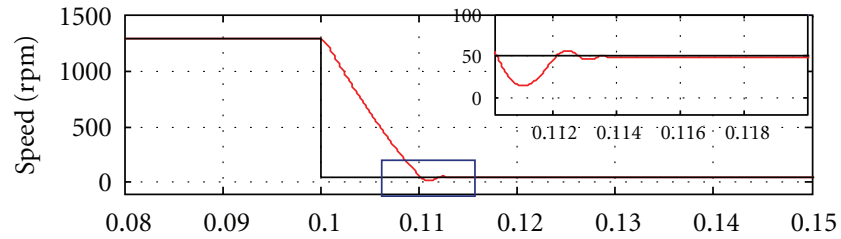

(b)

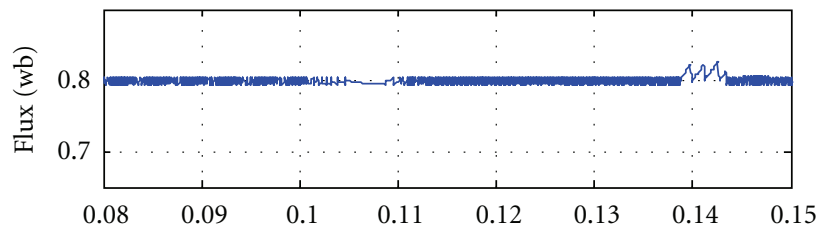

(d)

FIgure 10: Dynamic response for low-speed step transition (a) speed in rpm (low pass), (b) speed (Mod low pass), and (c) flux response (low pass), and (d) flux response (Mod Low pass).

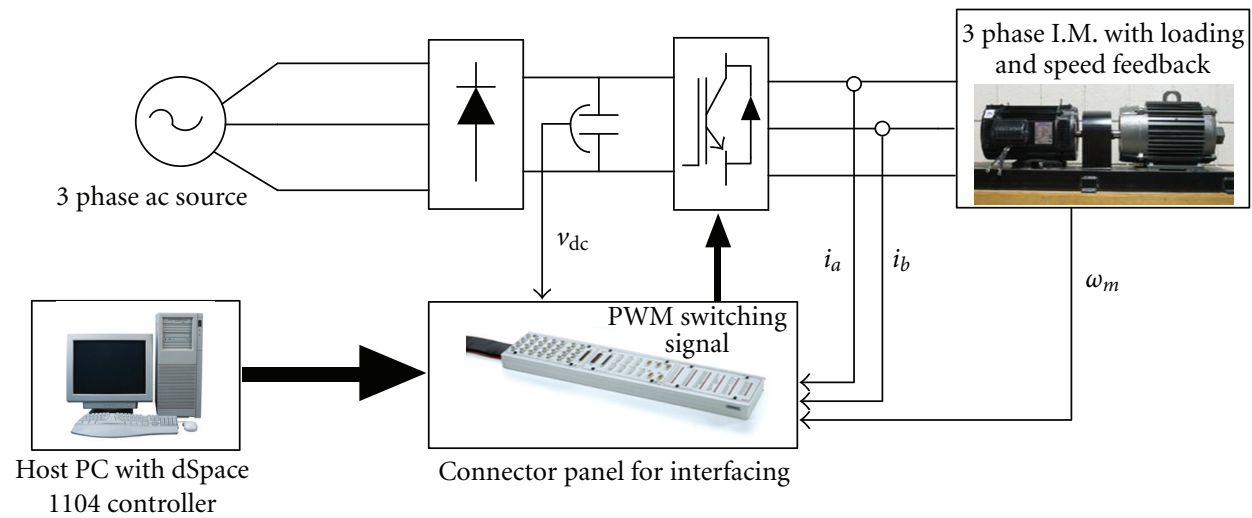

FIgURe 11: Experimental test drive set-up. 


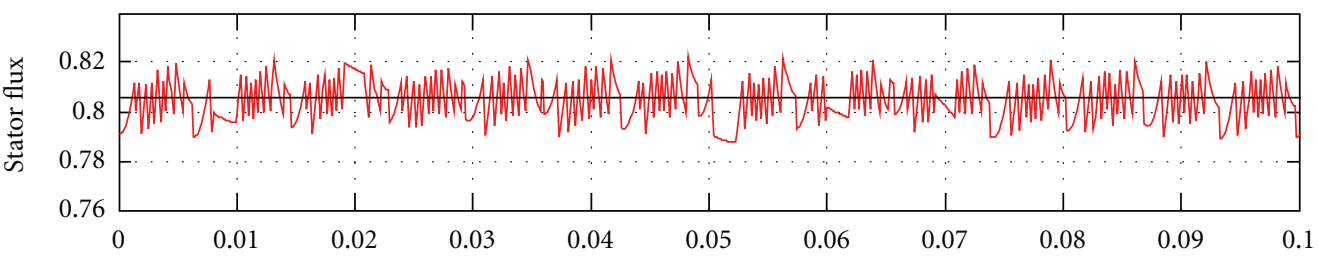

(a)

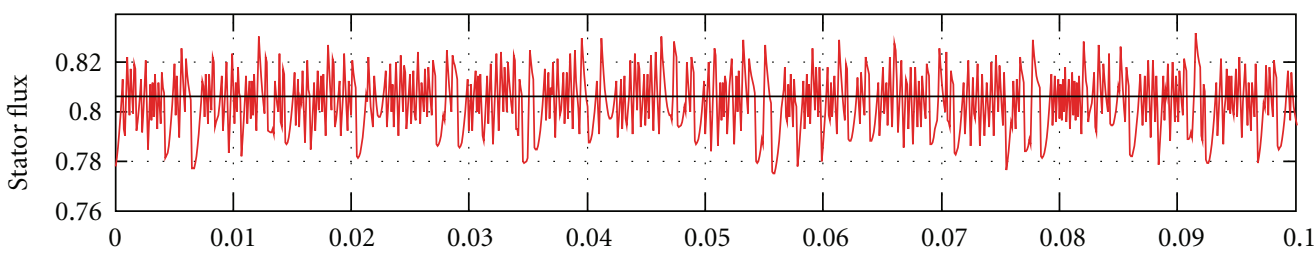

(b)

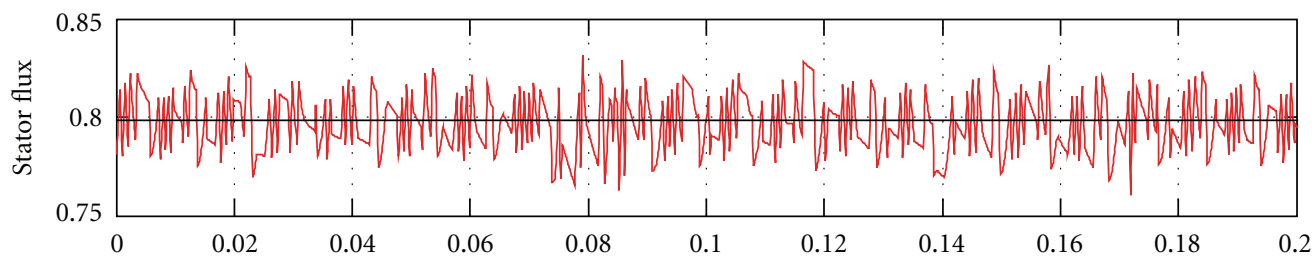

(c)

Figure 12: Experimentally obtained steady state flux response for low-speed operation (20\% rated speed) (a) Mod LPF, (b) LPF, and (c) pure integrator.

that the dynamic response of the Mod LPF flux estimation algorithm is the best compared to LPF and pure integration method. The time taken by the stator flux to attain the value of reference flux is the least in Mod LPF method.

In a LPF-based integration algorithm, the accuracy of determining the stator flux locus is affected by the cutoff frequency, and it can be verified from Figure 7, here the arrow marks points at the instants of wrong sector estimation and the corresponding distortion in stator flux. This distortion in stator flux due to the error in determining stator flux locus can be explained from Figure 8. By the basic principle of DTC operation for a counterclockwise rotation, when the stator flux vector is in sector 4 and if an increment in flux and torque is required, then the desired voltage vector should be $V_{5}$ Whereas it can be observed from Figure 7 that the location of stator flux is wrongly estimated in sector 5 (single arrow mark), and hence the appropriate voltage vector from the standard look up table for flux and torque increment in sector 5 will be $V_{6}$ as shown in Figure 8(b). Thus the wrongly selected voltage vector $V_{6}$ results in decrement of stator flux in sector 4 rather than its increment (double arrow marks), shown in Figure 7.

The influence of the feedback compensation term in the Mod LPF on the dynamic response of the drive was investigated by subjecting the drive to a sudden speed reversal command input and also by operating the drive with step reduction in operating speed from rated to very low speed (1300 to $50 \mathrm{rpm})$.

From Figures 9(a) and 9(c) it can be verified that during speed reversal a distortion in flux is observed at nearly zero speed crossing instant, while the Mod LPF shows a distortion free flux response during speed reversal instants as observed in Figures 9(b) and 9(d). Furthermore from Figures 10(b) and $10(\mathrm{~d})$ it can be concluded that the Mod LPF shows an improved flux response during low-speed operation of the drive. From the zoomed portion of the speed curve shown in Figure 10(a) it is observed that flux distortions at low-speed transition instants also results in speed overshoots and under shoots. This can be attributed to the fact that in the lowpass filter since at very low speeds the operating frequency of the drive becomes less than the cutoff frequency and hence distortions in flux are observed as seen in Figure 10(c).

4.2. Experimental Results. A test drive set-up developed in the laboratory to validate the simulation results is shown in Figure 11. The experimental test drive set-up consists of the following elements.

(1) Machine unit; a $0.75 \mathrm{~kW}, 410 \mathrm{~V}, 50-\mathrm{Hz}$ squirrel-cage induction motor with a shaft-mounted tachogenerator for speed sensing coupled with dc generator for loading.

(2) A power module with MOSFET-based voltage source inverter with Hall Effect sensors and gate drive circuitry.

(3) dSpace DS1104 control board.

The parameters of the motor for experimentation are as follows.

$R_{s}=10.75 \Omega, R_{r}=9.28 \Omega, L_{s}=L_{r}=51.9 \mathrm{mH}, P$ $=4$, and $L_{m}=479.9 \mathrm{mH}$. The sampling time of the DTC 


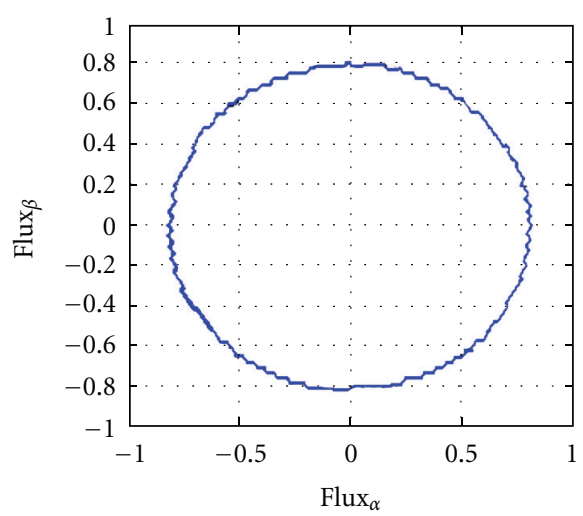

(a)

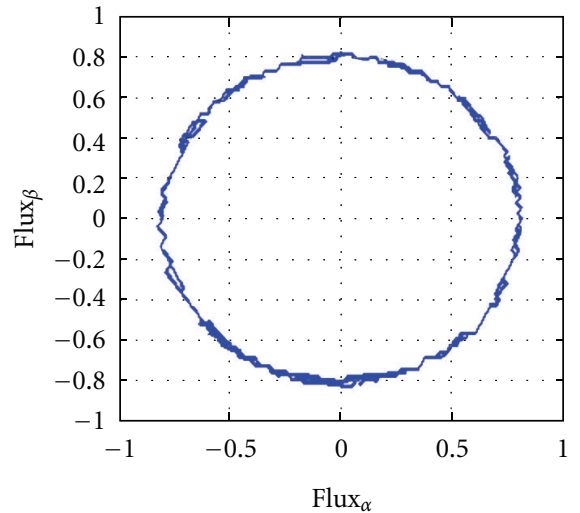

(b)

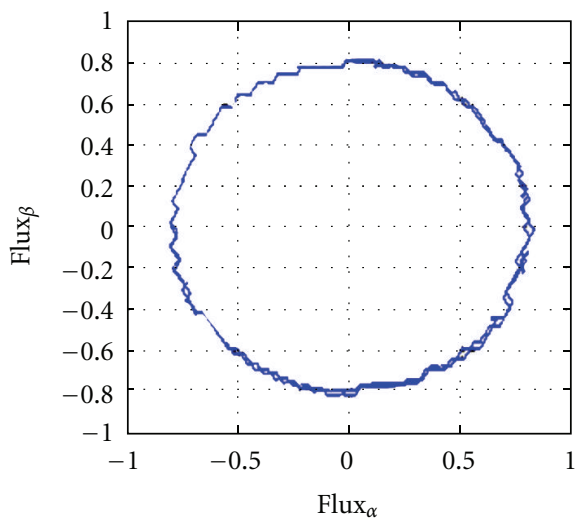

(c)

FIGURE 13: Stator flux trajectory at 20\% speed, (a) modified-low-pass filter integration algorithm, (b) low-pass filter integration algorithm, and (c) pure integration algorithm.

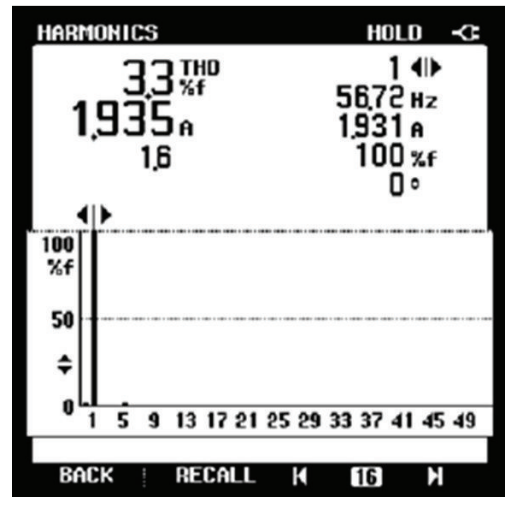

(a)

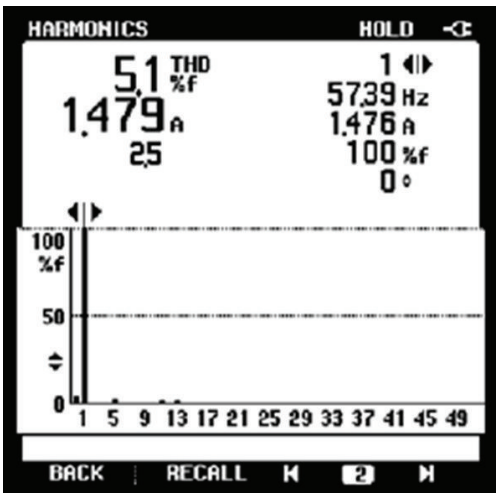

(b)

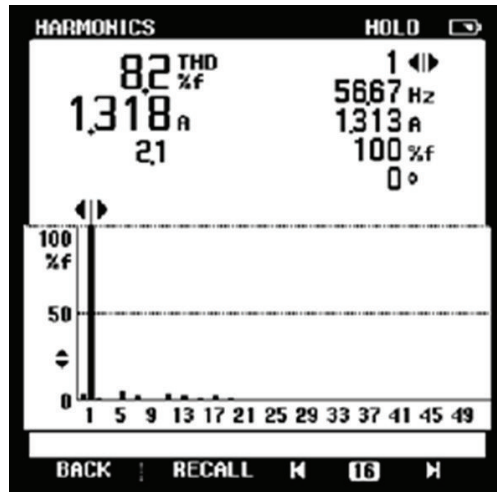

(c)

Figure 14: Stator current harmonics for 100\% load and $0.6 \mathrm{wb}$ ref flux (a) modified-low-pass filter, (b) low-pass filter, and (c) pure integrator.

experiments is taken as $100 \mu$ s while the dead time for the switches is $5 \mu \mathrm{s}$. The value of torque and flux hysteresis comparator bandwidth is takes as $0.5 \mathrm{Nm}$ and $0.005 \mathrm{wb}$. All experimental results are recorded using the control desk platform of dSpace DS1104.

The performance parameters to judge the effectiveness of the proposed integration algorithm are flux ripples and
Total Harmonic Distortion (THD) of the stator current. The flux ripples can be mathematically expressed by Root Mean Square Flux Error (RMSFE) given by (25):

$$
\operatorname{RMSFE}=\frac{1}{N} \sqrt{\sum_{k=1}^{N}\left(\lambda_{s}{ }^{\text {ref }}-\lambda_{s}(k)\right)^{2}},
$$




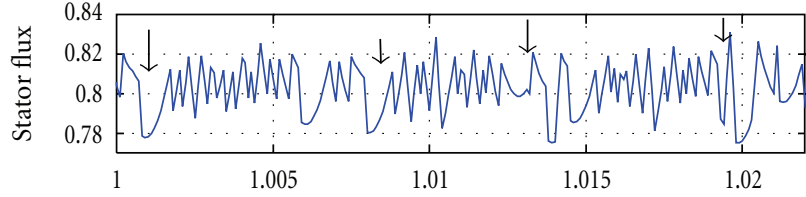

(a)

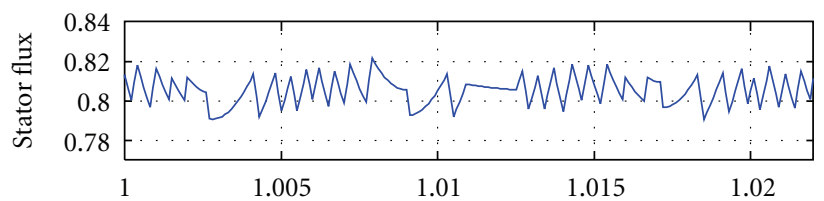

(c)

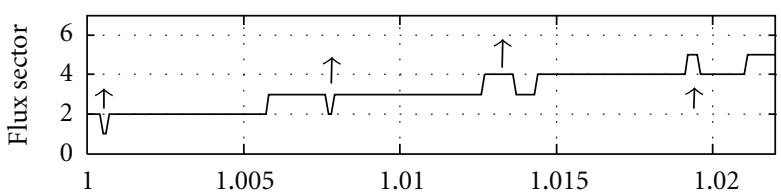

(b)

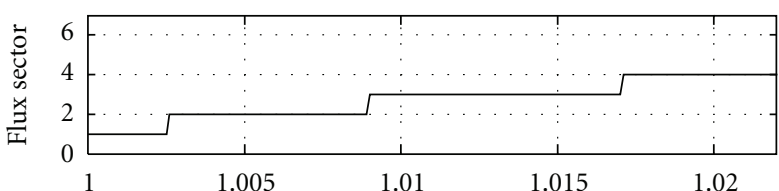

(d)

FiguRE 15: Experimental results showing stator flux distortion due to inaccurate sector estimation with LPF (a) stator flux, (b) stator flux sector, (c) an improved stator flux estimation in Mod. LPF method, and (d) stator flux sector.

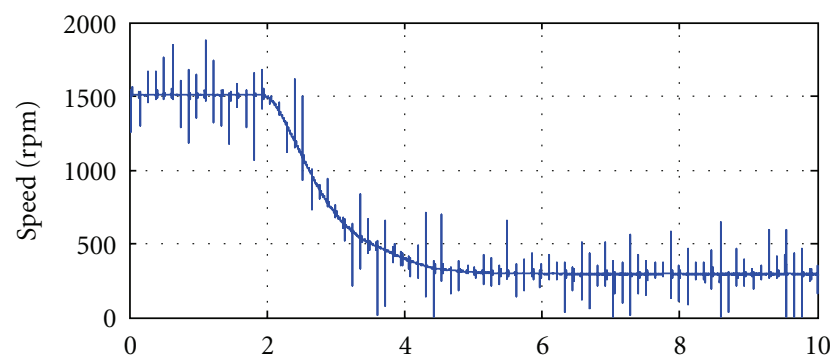

(a)

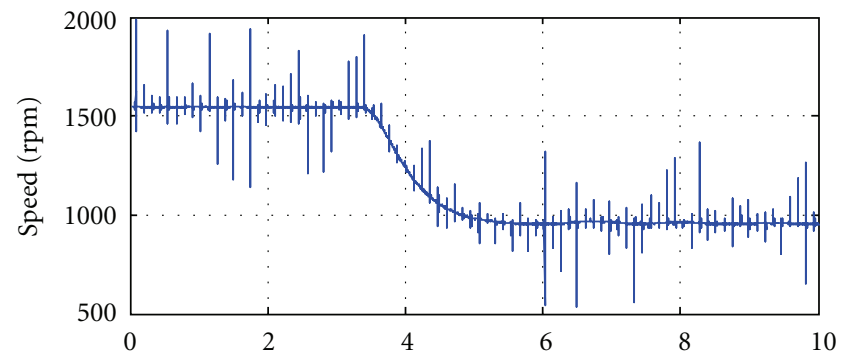

(c)

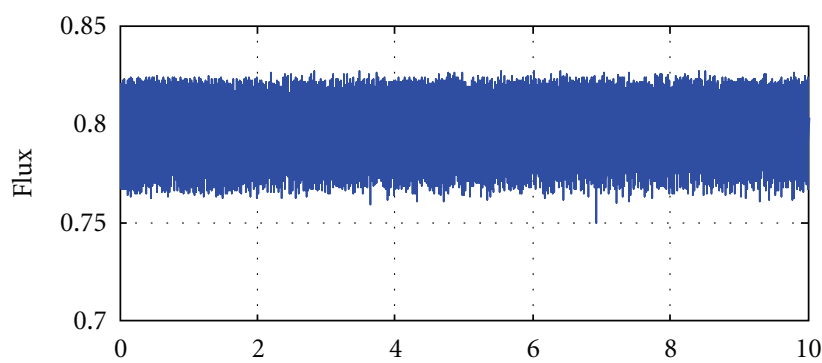

(b)

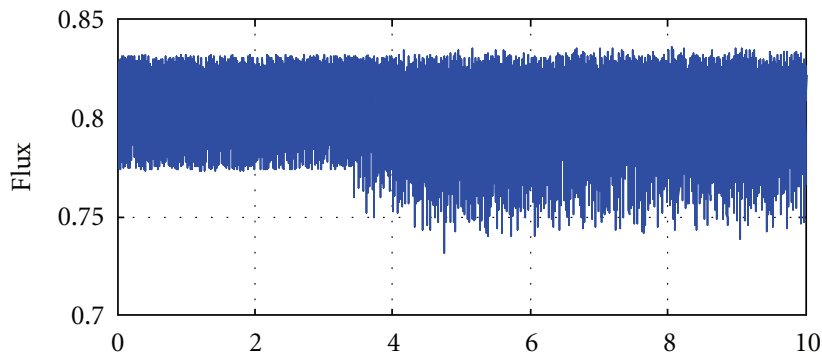

(d)

FIGURE 16: Flux response for step reduction in operating speed (a) speed in rpm, (b) stator flux for adaptive LPF method, (c) speed in rpm, and (d) stator flux for LPF method.

where $\lambda_{s}(k)$ and $\lambda_{s}$ ref are the estimated stator flux and reference flux at $K$ th and $(K-1)$ th sampling instant and $N$ is the number of data samples. The steady state flux ripples were studied for $100 \%$ and $30 \%$ loading of the machine at $80 \%$ rated speed. To judge the effectiveness of the flux estimation methods the test drive was operated with three different reference flux $0.6 \mathrm{wb}, 0.8 \mathrm{wb}$, and $1 \mathrm{wb}$, respectively. Furthermore to judge the low-speed performance of the flux estimation algorithm the experimental DTC drive was operated at $20 \%$ of the rated-speed.

The comparison of low-speed steady state flux response obtained using the three methods is shown in Figure 12. It can be verified from it that Mod LPF flux estimation algorithm shows minimum flux ripples in steady state condition. Table 1 shows the RMSFE calculated on the collected data samples of the estimated flux for $100 \%$ and
$30 \%$ loading, at $80 \%$ and $20 \%$ speed and with three different reference fluxes. The effectiveness of the Mod LPF flux estimation method in terms of flux ripples is validated from Table 1, where the RMSFE is the least for Mod LPF at all the operating flux and loading conditions during high- as well as low-speed operation. Since in the Mod LPF method, the presence of the feedback loop with compensation has a tight control over flux ripples, hence the stator flux is confined within the boundaries of the limits imposed by the control algorithm.

The superiority of Mod LPF in terms of stator flux trajectory over the other flux estimation methods is validated from Figure 13, here a circular locus of the flux vector with least distortion is observed. Mod LPF method also eliminates the harmonic distortion in stator current. Figure 14 shows the harmonic spectrum of stator current obtained through three 
TABLE 1: RMSFE for different flux estimation algorithms.

\begin{tabular}{|c|c|c|c|c|c|c|c|c|}
\hline \multirow{4}{*}{ Integration algorithm } & \multicolumn{6}{|c|}{ RMSFE (in percentage of ref Flux) at $80 \%$ rated speed } & \multirow{2}{*}{\multicolumn{2}{|c|}{$\begin{array}{c}\text { RMSFE at } 20 \% \text { speed } \\
100 \% \text { load }\end{array}$}} \\
\hline & \multicolumn{3}{|c|}{$100 \%$ load } & \multicolumn{3}{|c|}{$30 \%$ load } & & \\
\hline & \multicolumn{3}{|c|}{ Refrence stator flux } & \multicolumn{3}{|c|}{ Refrence stator flux } & \multicolumn{2}{|c|}{ Refrence stator flux } \\
\hline & $1.0 \mathrm{wb}$ & $0.8 \mathrm{wb}$ & $0.6 \mathrm{wb}$ & $1.0 \mathrm{wb}$ & $0.8 \mathrm{wb}$ & $0.6 \mathrm{wb}$ & $1.0 \mathrm{wb}$ & $0.8 \mathrm{wb}$ \\
\hline Mod. low pass & 1.02 & 1.24 & 1.77 & 1.03 & 1.2 & 1.62 & 0.83 & 0.9 \\
\hline low pass & 1.25 & 1.44 & 2.0 & 1.24 & 1.41 & 1.80 & 1.37 & 1.5 \\
\hline Pure integrator & 2.07 & 2.46 & 3.43 & 2.06 & 2.41 & 3.4 & 1.52 & 1.62 \\
\hline
\end{tabular}

TABLE 2: THD of stator current at different loadings.

\begin{tabular}{|c|c|c|c|c|c|c|}
\hline \multirow{4}{*}{ Integration algorithm } & \multicolumn{6}{|c|}{ Total harmonic distortion (in percentage) } \\
\hline & \multirow{2}{*}{\multicolumn{3}{|c|}{$\begin{array}{l}\quad 100 \% \text { load } \\
\text { Refrence stator flux }\end{array}$}} & \multirow{2}{*}{\multicolumn{3}{|c|}{$\begin{array}{c}30 \% \text { load } \\
\text { Refrence stator flux }\end{array}$}} \\
\hline & & & & & & \\
\hline & $1.0 \mathrm{wb}$ & $0.8 \mathrm{wb}$ & $0.6 \mathrm{wb}$ & $1.0 \mathrm{wb}$ & $0.8 \mathrm{wb}$ & $0.6 \mathrm{wb}$ \\
\hline Mod. low pass & 8.3 & 5.8 & 3.3 & 8.9 & 9.5 & 7.3 \\
\hline low pass & 11.4 & 8.2 & 5.1 & 12.1 & 11.8 & 9.2 \\
\hline Pure integrator & 13.8 & 12.4 & 8.2 & 14.5 & 14.7 & 12.2 \\
\hline
\end{tabular}

different estimation methods. THD for different loadings and flux are summarized in Table 2.

The experimental validation of the simulation results showing the distortion in stator flux in a LPF-based method due to error in sector estimation is shown in Figures 15(a) and 15(b). The instants of error in sector estimation and the corresponding distortion in stator flux are shown by arrow marks. The accuracy in sector estimation and the corresponding improvement in flux response for a Mod LPF method can be clearly observed in Figures 15(c) and 15(d).

The performance comparison of LPF and adaptive-lowpass filter method, when the drive is subjected to a step reduction in speed is shown in Figure 16. It can be verified from the figure that the flux ripples in a conventional LPF increases when there is a sudden reduction in speed, which is one of the limitations of a LPF having a fix cutoff frequency; while in an adaptive-low-pass filter, the cutoff frequency depends upon the operating synchronous frequency and hence the flux ripples remains constant when the drive is subjected to a step reduction in operating speed from $100 \%$ to $17 \%$ of its rated speed. The calculated RMSFE during speed decrement for an adaptive-low-pass filter is $1.55 \%$ while it is $2.25 \%$ for LPF.

\section{Conclusion}

This paper presents an investigation on flux response by different voltage-model-based flux estimation algorithm in a DTC drive. Flux ripples, stator current harmonics, and dynamic flux response are the considered performance parameters to judge the effectiveness of the estimation algorithm. The low-pass filter with feedback compensation flux estimation method (Mod LPF) proved to be superior in terms of flux ripples and stator current harmonics at rated as well as low-speed operation. The distortion in stator flux due to error in sector estimation is observed in a conventional LPF-based integration algorithm and the superiority of Mod LPF method in terms of mitigation of the above-mentioned problem is analyzed through simulation and validated experimentally. An improved dynamic flux response during speed reversal dynamics and sudden lowspeed transition also proves the merit of Mod LPF method.

The problem of selection of the cutoff frequency in lowpass-filter based integration algorithm, when the drive is subjected to large variation in operating speed is eliminated by an adaptive-low-pass filter having a cutoff frequency dependent on the electrical frequency of the drive.

\section{References}

[1] I. Takahashi and T. Noguchi, "A new quick-response and high efficiency control strategy of Induction Motor," IEEE Transactions on Industry Applications, vol. 22, no. 5, pp. 820827, 1986.

[2] M. Depenbrock, "Direct self-control (DSC) of inverter-fed induction machine," IEEE Transactions on Power Electronics, vol. 3, no. 4, pp. 420-429, 1988.

[3] G. S. Buja and M. P. Kazmierkowski, "Direct torque control of PWM inverter-fed AC motors-a survey," IEEE Transactions on Industrial Electronics, vol. 51, no. 4, pp. 744-757, 2004.

[4] G. Buja and R. Menis, "Steady-state performance degradation of a DTC IM drive under parameter and transduction errors," IEEE Transactions on Industrial Electronics, vol. 55, no. 4, pp. 1749-1760, 2008.

[5] M. H. Shin, D. S. Hyun, S. B. Cho, and S. Y. Choe, "An improved stator flux estimation for speed sensorless stator flux orientation control of induction motors," IEEE Transactions on Power Electronics, vol. 15, no. 2, pp. 312-318, 2000.

[6] E. D. Mitronikas and A. N. Safacas, "An improved sensorless vector-control method for an induction motor drive," IEEE Transactions on Industrial Electronics, vol. 52, no. 6, pp. 16601668, 2005.

[7] J. Holtz, "Sensorless position control of induction motorsan emerging technology," IEEE Transactions on Industrial Electronics, vol. 45, no. 6, pp. 840-852, 1998. 
[8] J. Holtz and J. Quan, "Drift- and parameter-compensated flux estimator for persistent zero-stator-frequency operation of sensorless-controlled induction motors," IEEE Transactions on Industry Applications, vol. 39, no. 4, pp. 1052-1060, 2003.

[9] K. D. Hurst, T. G. Habetler, G. Griva, and F. Profumo, "Zero-speed tacholess im torque control: simply a matter of stator voltage integration," IEEE Transactions on Industry Applications, vol. 34, no. 4, pp. 790-795, 1998.

[10] B. K. Bose and N. R. Patel, "A programmable cascaded low-pass filter-based flux synthesis for a stator flux-oriented vector-controlled induction motor drive," IEEE Transactions on Industrial Electronics, vol. 44, no. 1, pp. 140-143, 1997.

[11] J. Holtz and J. Quan, "Sensorless vector control of induction motors at very low speed using a nonlinear inverter model and parameter identification," in Proceedings of the 36th IAS Annual Meeting, vol. 4, pp. 2614-2621, October 2001.

[12] J. Hu and B. Wu, "New integration algorithms for estimating motor flux over a wide speed range," IEEE Transactions on Power Electronics, vol. 13, no. 5, pp. 969-977, 1998.

[13] M. Hinkkanen and J. Luomi, "Modified integrator for voltage model flux estimation of induction motors," IEEE Transactions on Industrial Electronics, vol. 50, no. 4, pp. 818-820, 2003.

[14] M. Bertoluzzo, G. Buja, and R. Menis, "A direct torque control scheme for induction motor drives using the current model flux estimation," in Proceedings of the IEEE International Symposium on Diagnostics for Electric Machines, Power Electronics and Drives (SDEMPED '07), pp. 185-190, September 2007.

[15] H. U. Rehman, A. Derdiyok, M. K. Guven, and L. Xu, "A new current model flux observer for wide speed range sensorless control of an induction machine," IEEE Transactions on Power Electronics, vol. 17, no. 6, pp. 1041-1048, 2002. 

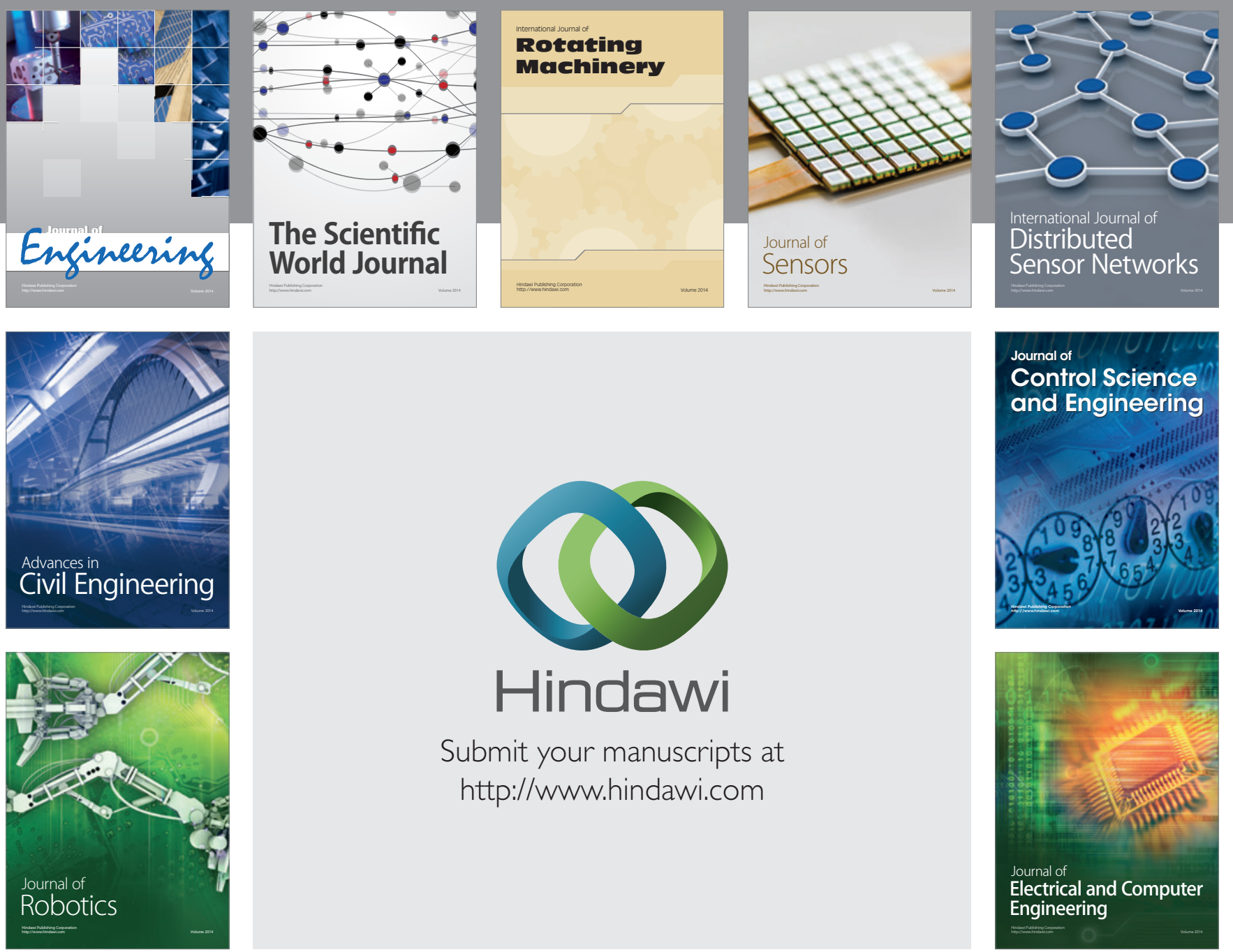

Submit your manuscripts at

http://www.hindawi.com
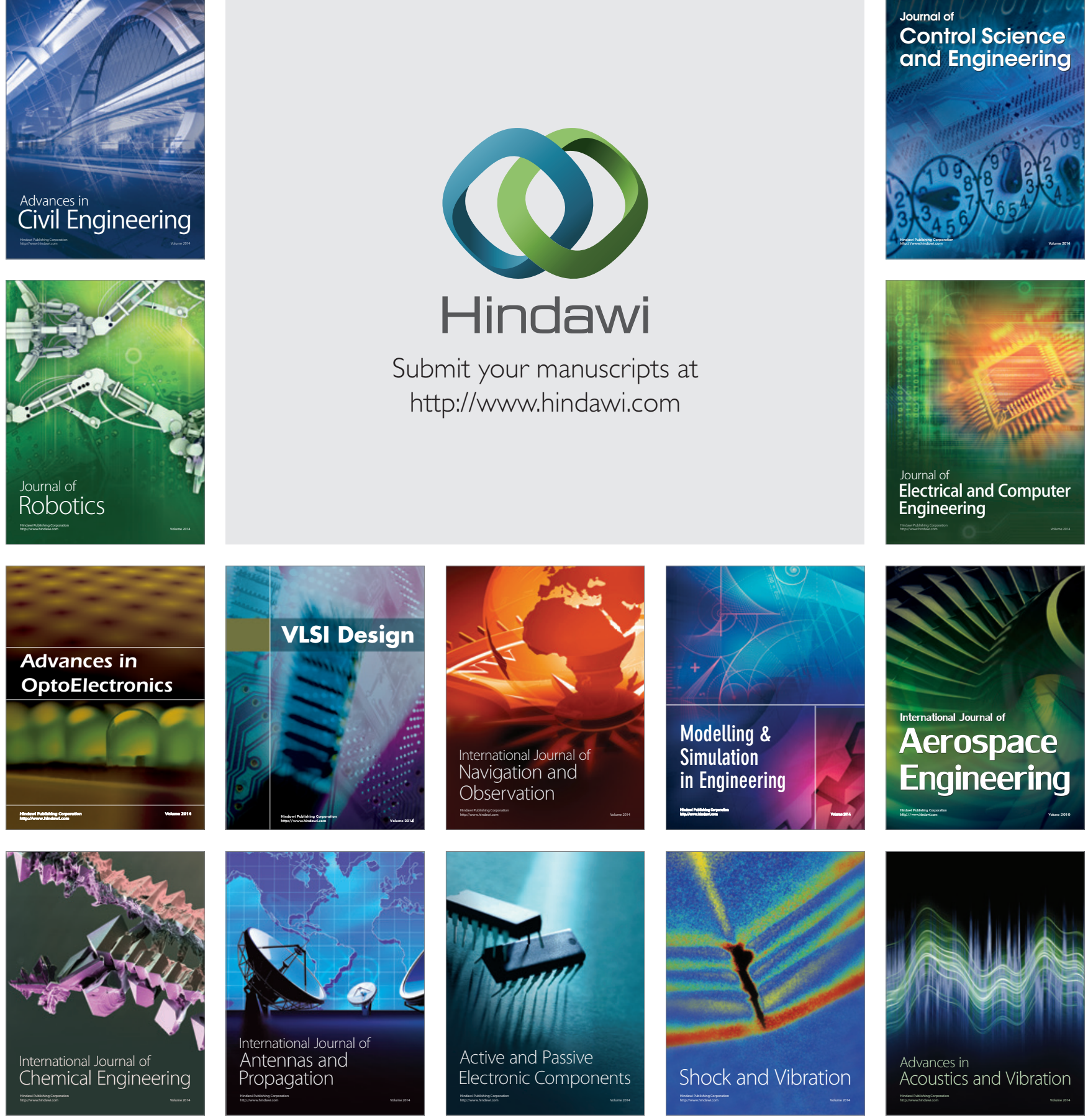